\title{
The Implementation And Application Of Firm Valuation Models
}

Christian Petersen, Copenhagen Business School, Denmark

Thomas Plenborg, Copenhagen Business School, Denmark

\begin{abstract}
This study focuses on methodological errors that arise when firm valuation is carried out in practice. Violation of assumptions underlying the valuation models are examples of methodological errors. We analyze valuation spreadsheets from five Danish financial institutions (i.e., stockbrokers and corporate finance departments) in order to trace if firm valuation models are properly applied. We conclude the following: (i) Methodological errors often cause valuation models to generate estimates that differ significantly from the theoretically correct value; and (ii) Firm value estimates were biased due to a variety of methodological errors. The implications of those errors may be significant. Investors are exposed to poor recommendations. Financial institutions such as investment bankers and stockbrokers may be exposed to bad reputation and lawsuits. Accounting firms that do not carry out firm valuation correctly (for example in testing goodwill for impairment) also run the risk of litigations.
\end{abstract}

Keywords: Firm valuation, valuation models, methodological errors, implementation.

\section{INTRODUCTION AND MOTIVATION}

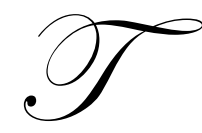

he purpose of our study is to document the existence of methodological errors, through an examination of the implementation and application of firm valuation models based on present value approaches (e.g., Discounted Cash Flow Model) in five Danish financial institutions (corporate finance and stockbrokers). As pointed out by Pratt et al. (2000) and Copeland et al. (2000) the Discounted Cash Flow model (DCF model), the residual income model (RI model) and other similar models based on capitalization of earnings are often used for firm valuation. As documented in extant literature these models yield identical results, that is, based on the same underlying assumptions these models are equivalents. In practice the implementation of different capitalization models may produce different results due to either (1) forecast errors (e.g., revenue growth and profit margins that are not based on sound economic reasoning) or (2) errors in the implementation and application of the valuation approach (i.e., methodological errors). The first type of errors is due to an over/underestimation of the true potential of a company and is difficult to avoid, although careful analysis mitigates this estimation error problem. The second type of errors, referred to as methodological errors, is caused by incorrect implementation and/or application of the valuation model. It is possible to avoid this type of errors if the user understands the underlying assumptions and carefully implements the valuation model (Lundholm and O'Keefe 2001a).

Penman and Sougiannis (1998), Francis et al. (2000) and Courteau et al. (2001) compare the accuracy of firm value estimates based on the dividend discount model (DDM), the DCF and the residual income (RI) approaches, respectively. They find that the residual income model yields more accurate firm value estimates than the DCF and DDM models. However, their findings are in conflict with the fact that the RI, DCF and DDM models are equivalents and, thus, from a theoretical perspective, must yield the same value estimates. ${ }^{1}$ If different present value models provide different results it must be due to improper implementation. Consequently, the studies conjecture that valuation models may yield different value estimates in practice as security analysts apply the models incorrectly (e.g., estimate the terminal value incorrectly). The studies, however, do not provide evidence that the implementation of valuation models is flawed. 
Sweeney (2002) and Lundholm and O'Keefe (2001a), among others, provide evidence that valuation models based on the present value concept yield exactly the same firm value estimates. Sweeney (2002) shows that accrual accounting models (e.g., RI-model) and cash flow models (e.g., FCF-model) provide the same value estimates if two conditions are met: (a) forecasts are internally consistent, and (b) discount rates are consistent with value additivity as derived by Modigliani and Miller (1958).

Lundholm and O'Keefe (2001a) list a number of assumptions that must be fulfilled in order to ensure proper execution and application of the present value approaches. They point out that 'even in a practical implementation or large sample study, the models should still be equivalent - for every firm in every year" (p. 315). Lundholm and O'Keefe (2001a) also detect a number of methodological errors in the studies by Penman and Sougiannis (1998), Francis et al. (2000) and Courteau et al. (2001), which they define as inconsistent forecasts errors, incorrect discount errors and missing cash flow errors, respectively. The relevance of the 'comparison studies' therefore relies on the conjecture that similar methodological errors are found in practice.

The purpose of our study is to examine if methodological errors like the ones found in Penman and Sougiannis, Francis et al. and Courteau et al are inherent in models used in practice. Thus, our study adds to the literature by providing direct evidence of errors committed in the implementation and application of valuation models.

The implications of methodological errors may be severe. For instance, investors are exposed to poor recommendations and financial institutions such as investment bankers, stockbrokers and accountants are exposed to bad reputation and lawsuits. Given the severe implications of methodological errors, it is surprising that no prior studies have examined how present value approaches are implemented and applied in practice by financial institutions.

This study proceeds as follow. The first section presents different valuation approaches. The second identifies and lists the requirement that must be met in order to ensure a proper implementation of present value approaches in firm valuation. The third section presents the sample and discusses methodological errors found in the examined spreadsheets. The final section concludes what might be learned from our study.

\section{TWO STAGE PRESENT VALUE APPROACHES}

There are two paths to firm valuation based on present value techniques: The first approach is to value equity only. These models include the DDM, (Model 1) and the RI, (Model 2).

The second path is to value the entire firm (enterprise value), which includes equity and interest bearing debt. These models include the DCF (Model 3) ${ }^{2}$ and Economic Value Added (EVA) (Model 4). According to Copeland et al. $(2000,131)$ the DCF model is the most popular valuation technique in practice. The DCF approach is outlined below:

$$
E V_{t}=\sum_{\tau=1}^{T} \frac{F C F_{t+\tau}}{\prod_{j=1}^{\tau}\left(1+W A C C_{t+j}\right)}+\frac{F C F_{T+1}}{W A C C_{T+1}-g} \cdot \frac{1}{\prod_{j=1}^{T}\left(1+W A C C_{t+j}\right)}
$$

$\begin{array}{ll}\text { EV } & =\text { Enterprise value } \\ \text { WACC } & =\text { Weighted average cost of capital } \\ \text { FCF } & =\text { Free cash flow to firm } \\ \text { IC } & =\text { Invested capital } \\ \text { EVA } & =\text { Economic value added } \\ \mathrm{g} & =\text { Growth rate in FCF }\end{array}$


A variant of the second approach (Models 3 and 4) is the adjusted present value approach, APV (Model 5) that values the effect of financing separately (tax advantage from interest bearing debt). As demonstrated in Penman (1997) and Levin (1998) all five valuation approaches (Models 1 - 5) are equivalents. Using the same data (proforma financial statements) the five valuation approaches will yield exactly the same firm value estimates. However, as demonstrated in the next section, it is easy to violate the internal coherence in the valuation approaches. As a consequence firm value estimates may be biased.

\section{The Assumptions Behind The Two Stage Present Value Approach ${ }^{3}$}

A number of assumptions are inherent in present value models. If these assumptions are violated the Models $1-5$ will not provide the exact same firm value estimates. The major assumptions are as follows:

\section{Cost of capital;}

1. Capital structure must be based on market values.

2. Cost of capital must reflect changes in the capital structure.

Pro forma financial statements;

3. The cash flows in the explicit forecast period must be based on coherent pro-forma financial statements.

4. DCF- and APV models recognise that all excess cash is assumed to be invested in projects with a NPV equal to zero.

Terminal values;

5. Cash flows must be based on coherent pro-forma financial statements.

6. Cash flows in the terminal period must grow at a constant rate.

The three categories above match the ones that Levin (2000) and Lundholm and O'Keefe (2001a) list. ${ }^{4}$ A more detailed description of each assumption is given below.

According to the first assumption a firm's capital structure must be based on market values to reflect the true opportunity costs. Book value of debt and equity may be poor proxies for market values. For instance, book value of net assets (equity) reflects a mix of assets valued at historical prices (e.g., tangible fixed assets measured at costs less accumulated depreciation) and fair value (e.g., financial assets). Also, some assets that are valued by the market are expensed, as they do not satisfy recognition criteria for assets. Hence, book values may differ substantially from market values. This has also been pointed by Copeland et al. (2000), among others.

According to the second assumption cost of capital must reflect both the current and future capital structure, which implies that discount rates must reflect changes in the capital structure. Violation of the second assumption only matters in cases of significant changes in the capital structure (Levin and Olsson 1998; Copeland et al. 2000, 203). In Lundholm and O'Keefe (2001a) these types of errors are defined as the 'incorrect discount error'.

The third and fifth assumptions are similar in nature. They both require that estimated cash flows are generated from a coherent budget. This implies that the income statement, balance sheet and cash flow statements articulate; the use of a so-called 'plug' in order to make assets and liabilities balance is not allowed. Lundholm and O'Keefe $(2001 b, 696)$ also make the point that it is important to apply 'full pro-forma financials'.

According to the fourth assumption, all excess cash is invested in projects with a net present value equal to zero (Palepu et al. 1996). This implies that excess cash generated in the forecast period neither adds nor destroy value.

The final assumption requires that all parameters grow at the same rate in the terminal period, while the capital structure remains constant. If Gordon's growth model $^{5}$ is used to estimate the terminal value, Levin and Olsson (2000) demonstrate that it is necessary to forecast income statements, balance sheets and cash flows two years into the terminal period to ensure that all variables grow at the same rate (steady state assumption). In fact, if 
certain variables (accounting numbers) are unrelated to the primary value driver (typically turnover) ${ }^{6}$ it may be necessary to forecast more than two years into the terminal period to ensure that all variables grow at the same rate.

Lundholm and O'Keefe (2001a, 330) make a similar point. If terminal value is estimated based on the convergence model ${ }^{7}$, the need to make explicit forecasts into the terminal period depends on the value driver set-up. Again, it is necessary to forecast into the terminal period if certain accounting variables are not linked to the primary value driver (i.e., turnover). ${ }^{8}$

\section{EMPIRICAL ANALYSIS}

This section describes the sample and discusses if the five valuation models provided by large Danish financial institutions comply with the assumptions underlying present value models presented above (Models 1 - 5). We also discuss the significance of errors.

\section{Sample}

The market for equity analysis in Denmark is limited to a few large players and relatively few other players. All major players, totalling 15, within corporate finance and stock analysis were contacted and offered to have their spreadsheet models examined. Five of the financial institutions accepted to participate in our analysis. Despite the relatively small sample it does cover major areas where valuation approaches are applied frequently. The 15 financial institutions account for $90 \%-95 \%$ of the market for corporate finance and stock analysis in Denmark. ${ }^{9}$ The relatively low number of participants reflects that the financial analysts considered their spreadsheet models a trade secret. None of the five participants allowed us to reveal their identity in the analysis. We can only convey that the five financial institutions are all medium to large players. They can be separated into two distinct groups:

- $\quad$ Two participants from corporate finance

- $\quad$ Three participants from stock analysis

All five spreadsheets contained a two-stage discounted cash flow model (DCF) as shown in Equation 1. Two of the spreadsheets included an EVA model. The EVA model was not considered as the primary model for firm valuation purposes, but was used purely as a control mechanism. ${ }^{10}$ Since the DCF and EVA valuation approaches ought to yield identical values, the financial analysts argue that applying two different models is an effective way to detect methodological errors. ${ }^{11}$

Table 1 presents a short description of the five Microsoft Excel spreadsheets (valuation models).

The five models we analyzed were standard valuation models, that is, each of the five financial institutions constructed their own standard model. Only in one case (spreadsheet V) did the financial analysts have more than one standard model to choose from.

In some cases the financial analysts were allowed to change the underlying model. We observed that analysts changed the model(s) if they had this option. This approach allows more flexible models; however, it also increases the risk of errors. The fact that analysts are allowed to make modifications to standard model(s), reinforces that specialists within the financial institution should examine the models carefully in order to avoid methodological errors. Apparently a check of the validity of the models by others than the financial analysts were not carried out in at least two cases, as there were no persons in charge of maintaining spreadsheets II and IV, respectively. 
Table 1

Comparing the set-up for the five valuation models

\begin{tabular}{|c|c|c|c|c|c|}
\hline & 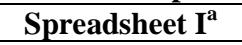 & Spreadsheet II & Spreadsheet III & Spreadsheet IV & Spreadsheet V \\
\hline $\begin{array}{l}\text { Do all analysts apply the } \\
\text { same valuation model }\end{array}$ & Yes & Yes & Yes & Yes & $\begin{array}{l}\text { No, can choose } \\
\text { among three } \\
\text { standard models }\end{array}$ \\
\hline Standard model & Yes & Yes & Yes & Yes & $\begin{array}{l}\text { Yes, three } \\
\text { different } \\
\text { standard models }\end{array}$ \\
\hline $\begin{array}{l}\text { Analysts allowed to } \\
\text { adjust standard model }\end{array}$ & No & Yes & Yes & Yes & No \\
\hline $\begin{array}{l}\text { Analyzed model } \\
\text { adjusted by user }^{\mathrm{b}}\end{array}$ & No & Yes & Yes & Yes & No \\
\hline $\begin{array}{l}\text { Person in charge of } \\
\text { developing/maintaining } \\
\text { standard model }\end{array}$ & Yes & No & Yes & No & Yes \\
\hline Interviews & $\begin{array}{l}\text { With manager of } \\
\text { security analysis }\end{array}$ & $\begin{array}{l}\text { With two daily } \\
\text { users }\end{array}$ & $\begin{array}{l}\text { With manager of } \\
\text { security analysis }\end{array}$ & $\begin{array}{l}\text { With two daily } \\
\text { users }\end{array}$ & $\begin{array}{l}\text { With manager of } \\
\text { security analysis }\end{array}$ \\
\hline \multicolumn{6}{|c|}{$\begin{array}{l}\text { Notes: } \\
\text { a. Model is a spreadsheet valuation model developed in Microsoft Excel 2000/XP. } \\
\text { b. Analyzed model adjusted by user: The user(s) of the model(s) have changed the standard valuation model (before applying } \\
\text { input to the model). }\end{array}$} \\
\hline
\end{tabular}

\section{Empirical Results}

We examined the validity of the five spreadsheets in a two step process. First, we estimated firm value by keying in the exact same set of forecast assumptions (e.g. turnover growth rate, profit margin, turnover ratio, etc.) in each spreadsheet. The estimated value differed substantially between the five spreadsheets, which supported our hypothesis that firm valuation models are inappropriately applied. Second, in order to further examine if each of the spreadsheets is consistent with the six assumptions a thorough analysis was performed. For example, to examine if the spreadsheets comply with assumptions 3 and 5 (cash flows are based on coherent pro-forma financial statements) we checked each models' bookkeeping, and found various errors such as miscalculating working capital, cash flows and shareholders equity. Some spreadsheets also allow a "plug" value in the sense that one of the items under liabilities is determined as the residual (typically the item 'other creditors') that ensures that assets and liabilities balance. In addition we found simple spreadsheet errors such as sign errors and incorrect cell references. For example, in one spreadsheet shareholders equity increased when dividend was paid out to the shareholders. In another spreadsheet an increase in inventory had a positive impact on FCF.

We examined if each of the spreadsheets was consistent with the six assumptions by following the 'cell-bycell code inspection procedure'. This has also been suggested by Panko (2000). He argues that to date, only one technique, 'cell-by-cell code inspection', has been demonstrated to be effective in detecting simple spreadsheet errors. Poor designing of the models (they were clearly not intended to be used by third parties) and the lack of system documentation made the 'cell-by-cell code inspection procedure' a difficult and time consuming task.

In addition, we interviewed the financial analysts in order to support our findings. ${ }^{12}$ The interviews provided us with an in-depth understanding of how the spreadsheets were constructed and helped us to clarify unsolved questions that arose from the analysis. Specifically, we gained a deeper understanding of the assumptions introduced by the analysts and clarified a variety of questions that came up in connection with the analysis.

The results from the analysis of the five spreadsheets are summarized in table 2. 
Table 2

Overview of the results Model No.

\begin{tabular}{|c|c|c|c|c|c|}
\hline Assumption No. & I & II & III & IV & $\mathbf{V}$ \\
\hline \multicolumn{6}{|l|}{ Cost of capital } \\
\hline 1 & $\sqrt{ }$ & $\sqrt{ }$ & $\sqrt{ }$ & $\sqrt{ }$ & $\sqrt{ }$ \\
\hline 2 & $\div$ & $\div$ & $\div$ & $\div$ & $\div$ \\
\hline \multicolumn{6}{|c|}{ Pro forma financial statements } \\
\hline 3 & $\sqrt{ }$ & $\div$ & $\div$ & $\div$ & $\sqrt{ }$ \\
\hline 4 & $\sqrt{ }$ & $\sqrt{ }$ & $\sqrt{ }$ & $\div$ & $\sqrt{ }$ \\
\hline \multicolumn{6}{|l|}{ Terminal values } \\
\hline 5 & $\sqrt{ }$ & $\div$ & $\div$ & $\div$ & $\sqrt{ }$ \\
\hline 6 & $\div$ & $\div$ & $\sqrt{ }$ & $\div$ & $\sqrt{ }$ \\
\hline
\end{tabular}

Notes:

Assumptions Nos. 1-6 are described in the section: 'The assumptions behind the two stage present value approach'. The assumptions are as follows:

1. Capital structure must be based on market values.

2. Cost of capital must reflect changes in the capital structure.

3. The cash flows in the explicit forecast period have to be based on coherent pro-forma statements.

4. The DCF- and APV models rely on the assumption that all excess cash is invested in projects with a NPV equal to zero.

5. Cash flows must be based on coherent pro-forma financial statements.

6. Cash flows in the terminal period must grow at a constant rate.

$\sqrt{ }=$ Assumption not violated (e.g. $\sqrt{ }$ next to assumption 1 indicates that capital structure is based on market values) $\div=$ Assumption violated

In the following section we will elaborate on the empirical results reported in table 2.

\section{Correct Cost Of Capital (Assumptions 1-2)}

Spreadsheets I-V comply with assumption (1) that the capital structure must be based on market values. Financial analysts who carry out stock analysis (spreadsheets I - III) apply current market values of debt and equity to estimate the capital structure. Companies in Denmark are not required to report the market value of interest bearing debt and only a few companies report this piece of information on a voluntary basis. If the market value of interest bearing debt is not reported, book value is used as a proxy. ${ }^{13}$ If a company operates with a target capital structure, the financial analysts applying spreadsheets I, II and III generally use this target to estimate the cost of capital. In the remaining spreadsheets (IV and V) the market value of equity was primarily found through an iteration procedure. The capital structure from a peer group was used as a supplement to the iteration procedure. The financial analysts considered the iteration procedure as useful since they primarily value privately held firms, where no market values for debt and equity are available.

None of the five spreadsheets comply with assumption (2) that the cost of capital must reflect changes in the capital structure. The stock analysts (spreadsheets I - III) apply current market values as their best estimate for the long term capital structure. Corporate finance analysts (spreadsheets IV and V) estimate the current capital structure through an iteration process without taking into account future changes in the capital structure. Levin and Olsson (1998) evaluate the economic consequences of violating the second assumption and find that small to modest changes in the capital structure only have a minor effect on firm value. However, significant changes in the capital structure (e.g., LBO) may have a substantial impact on the firm value.

\section{Correct Pro Forma Financial Statements (Assumptions 3-4)}

In spreadsheets II, III and IV the internal coherence between the income statement, balance sheet and cash flow statement is violated, which is also a violation of the third assumption. In model II and III the violation is a result of assigning a wrong sign to accounting variables (e.g., revenues become expenses) and/or incorrect cell references. 
It is notable that simple spreadsheet errors were detected in spreadsheets that allow for individual adjustments. This indicates that spreadsheet models that do not offer individual adjustments should be preferred even though it reduces the models flexibility. This minimizes the risk of simple spreadsheet errors that in several cases have a significant impact on firm value estimates. The significance of simple spreadsheet errors is entirely dependent on the specific case (firm) and the type of error. The point to make is that these errors would not occur if the valuation models were carefully implemented.

In spreadsheet IV budgeting is typically based on forecasts provided by clients. However, due to the nature of spreadsheet IV it is almost impossible to carry out sensitivity analysis without violating the internal coherence between the income statement, balance sheet and cash flow statement.

In spreadsheets I, II, III and V interest bearing debt is net of excess cash. This procedure ensures that all excess cash is invested in projects with a net present value equal to zero. All four spreadsheets therefore comply with the fourth assumption. However, the above treatment of excess cash creates another problem as the debt to equity ratio will eventually turn negative due to excess cash in future periods. This is not captured in any of the four models as they operate with a constant capital structure. The impact of the error equals the present value of tax savings from interest bearing debt (from the use of a constant capital structure). In spreadsheet IV excess cash is added to the cash position, however, interest income is not recognized in the pro-forma financial statements. Consequently, spreadsheet IV does not comply with the fourth assumption. Further, capital structure is affected in the same way as in the four other spreadsheets, which will also bias firm value estimates.

\section{Correct Terminal Values (Assumptions 5-6)}

In two of the spreadsheets (II and IV) the cash flows are not based on a coherent budget, which is a violation of the fifth assumption. In spreadsheet II the free cash flow in the first year of the terminal period is estimated by multiplying the free cash flow from the last year of the explicit forecast period by one plus the assumed growth rate ${ }^{14}$ This is incorrect since a change in the growth rate $(g)$ in the first year of the terminal period will affect the level of investments in working capital and fixed assets. A lower growth rate implies, other things being equal, fewer investments and, consequently, a higher free cash flow. Spreadsheet IV relies on the improper assumption that growth is for free. The only type of investments in spreadsheet IV is reinvestments. Thus, if growth is introduced in the terminal period it does not have any impact on the level of investments, clearly a heroic assumption.

In spreadsheet III the free cash flow in the terminal period is estimated through pro-forma financial statements but there is no control mechanism to ensure that these statements articulate. In addition, the assumption (5) is also violated when sensitivity analysis is carried out. When the financial analyst changes the growth rate $(g)$ it does not have any impact on the pro-forma financial statements (e.g. revenues). Rather, the adjustment in $g$ enters directly into the valuation model. ${ }^{15}$ Thereby, the financial analyst assumes that growth can deviate from the base scenario, while investments (incorrectly) remain unchanged. Various sensitivity tests document that a violation of the fifth assumption has a significant impact on firm value estimates (see 'Significance of errors' below).

In spreadsheets I and V the free cash flow or NOPLAT ${ }^{16}$ in the terminal period is found through a coherent budget. Spreadsheets I and V therefore comply with the fifth assumption.

Several of the spreadsheets do not comply with the assumption that cash flows in the terminal period must grow at a constant rate (assumption 6). Spreadsheets I, III and V all assume that growth does not add value, i.e. the net present value of new investments equals zero. As a result terminal value is calculated as NOPLAT/WACC. All three spreadsheets therefore seem to comply with the sixth assumption. However, in spreadsheet I depreciation is calculated as a percentage of fixed assets at the beginning of the period. As a direct consequence the sixth assumption is violated; NOPLAT is generally overvalued/undervalued (depreciations too low/too high) as reinvestments are underestimated/ overestimated.

In spreadsheet II the terminal period consists of two separate time periods. The first part of the terminal period span over ten years and in that period the FCF is reduced by one percent per year. In the second part of the 
terminal period the free cash flow $\left(\mathrm{FCF}_{\mathrm{T}+1}\right)$ is calculated as $\mathrm{FCF}_{\mathrm{T}} \cdot(1+\mathrm{g})$ and the terminal value is calculated as FCF/WACC. As stated previously $\mathrm{FCF}_{\mathrm{T}+1}$ is not properly measured. Further, $\mathrm{FCF}_{\mathrm{T}+1}$ is not generated from an underlying coherent budget but rather from a simple extrapolation. Thus, it is difficult to determine whether the 'underlying' $\mathrm{FCF}_{\mathrm{T}+1}$ is growing at a constant rate.

Spreadsheet IV calculates terminal value as $\frac{F C F_{T+1}}{W A C C-g}$ where $\mathrm{FCF}_{\mathrm{T}+1}$ equals the FCF from year one in the terminal period. According to Levin and Olsson (2000) and Lundholm and O'Keefe (2001a) this is a problem since FCF may not be growing at a constant rate after the first year in the terminal period. Although $g$ is allowed to be positive in spreadsheet IV it is not possible to carry out any new investments in the terminal period (beyond reinvestments). As a consequence, FCF is not growing at a constant rate $(g)$ and the capital structure is not constant in the terminal period. Thus, spreadsheet IV clearly violates the sixth assumption. Various sensitivity tests document that a violation of the sixth assumption has a significant impact on firm value estimates (see 'Significance of errors' below).

Based on the analysis of the five spreadsheets it is evident that violation of the assumptions concerning the terminal value calculation becomes critical (see below). The interviews also revealed that the financial analysts were generally not aware that they violated some of the assumptions. They were also surprised by the big impact that a violation of the assumptions concerning the terminal value has on the estimates. The results corresponds with Penman $(1997,303)$ who argues that 'terminal values often have a significant effect on valuation but their calculation is sometimes ad hoc or relies on doubtful assumptions'.

\section{Significance Of Errors}

Estimating firm value is not an exact science. Even though careful analysis of a firm's strategy, historical financial statements, and other sources of information alleviate the estimation error problem, we acknowledge that firm value still depends on highly uncertain future cash flows. In our opinion this accentuates that firm valuation ought to be free of methodological errors, as such errors can be avoided if analysts' possess adequate knowledge of firm valuation techniques and are precise in the implementation of valuation models.

Ideally, we prefer to estimate the significance of the different errors in the valuation models we analyzed. For example, how much (in percent) do firm value estimates from these models differ from estimates produced by an error free model, if, for instance, the assumption that the free cash flows in the terminal period must grow at a constant rate is violated (assumption 6). However, for a variety of reasons such calculations can hardly be made in a meaningful way. At the very best we would be able to come up with some very crude estimates of the magnitude of each separate error.

As a starting point we would have to estimate firm value 'as if' each provided valuation model was error free. In essence, this means that we would have to 'fix' each of the five models to ensure that they contain no methodological errors. A careful examination of the models revealed that they were constructed differently, lack system documentation, and are not all well organized (e.g., input must be keyed in into more than one sheet) etc. Consequently, it would be an extremely time consuming task to track every single error and make the proper adjustments to the models.

The magnitude of the errors is obviously case specific, that is, the bias in the firm value estimate depends on the firm that the analysts try to value. For example, the error committed in one of the models, which incorrectly modelled that an increase in inventory had a positive impact on the free cash flow (FCF), may be substantial if the firm valued is a retail company with large inventories. However, the error may be insignificant if a firm within the service industry is valued.

The spreadsheets contain several errors that surely interact. These errors may offset each other or move in the same direction. Therefore, it is difficult to isolate the effect of each separate error. A case in point is the use (and misuse) of the growth factor $(g)$ in terminal value calculations. Some analysts incorrectly calculate the free cash 
flow in the terminal period as the free cash flow the year before multiplied by one plus the assumed growth rate in the terminal period. Thus, value added in the terminal period amounts to: $\left(\mathrm{FCF}_{\mathrm{T}} \cdot(1+\mathrm{g})\right) /(\mathrm{WACC}-\mathrm{g})$. It may be possible to 'fix' the free cash flows, but this also implies that the denominator $(g)$ should be changed.

Another approach is to examine the significance of errors by introducing these errors (one at a time) in our control model. ${ }^{17}$ We decided to estimate the magnitude of errors by 'crashing' our control model, that is, introduce errors like the ones found in the spreadsheets provided by the financial institutions. Naturally, this procedure does not eliminate the problem that the significance of the errors is case specific; however, it does give an indication of which errors are the most severe.

This approach, however, also has its shortcomings. For instance, often growth in the free cash flows (FCF) in the terminal period is incorrectly estimated, that is, FCF has not yet reached 'steady state'. In 'steady state' all accounting variables (parameters) grow at the same rate $(g)$. The significance of this error depends on how much value is created in the terminal period.

Further, only a few value drivers are needed in our control model. In the analyzed models, however, the value driver set-ups were quite different from ours. In fact, the five models we analyzed each have unique set-ups with as much as 25 value drivers. This begs the questions: How do we key in our pro-forma financial statements in the models provided by the five financial institutions? For instance, if investments are not tied to revenues (the primary value driver in our set-up), should we then key in numbers which ascertain that investments are directly linked to revenues (e.g., investments is constantly calculated as $10 \%$ of revenues), and, if not, how would we be able to determine what figures the financial analysts would have used?

Appreciating that determining the significance of methodological errors is highly uncertain, we were able to come up with some rough estimates. Violating the assumptions behind the cost of capital calculations (assumptions 1 and 2) account for a bias in firm valuation of $8 \%-10 \%$. However, the estimate is sensitive and assumes that the cost of capital reflects that book values of equity and debt deviate from their market values (assumption 1) or fluctuates over time (assumption 2).

The significance of errors related to assumptions 3 to 4 could not be estimated as they constitute a variety of different violations. However, the errors may be quite significant. For instance, changing the sign on inventory (an error actually detected) provided an error in firm value of approximately $7 \%{ }^{18}$ Finally, violations of the assumptions behind the terminal value calculations were the most severe. Depending on the model we analyzed the error amounted to anywhere between $20 \%$ and $250 \%$.

Again, the significance of errors should not be taken at face value. The calculations are highly uncertain, and are based on a number of implicit assumptions. It seems warranted, however, to conjecture that methodological errors related to terminal value calculations are the most severe. This is in line with previous studies on firm valuation (Penman, 1997).

\section{CONCLUSION AND PERSPECTIVES}

A potential problem in our study is self-selection bias, i.e. the five institutions that participated did so because they expected that they might have implemented the valuation models incorrectly. This problem is not easily overcome. ${ }^{19}$ Thus, the results reported in this study may not necessarily be generalised to other financial institutions.

Our results reveal that all five valuation models (spreadsheets) were all flawed to some extent. Some of the spreadsheet errors had a significant impact on the firm value estimate. The most frequent (and critical) violation involve calculation of the terminal value. Further, all spreadsheets violate the assumption that cost of capital must reflect changes in the capital structure. However, this violation was purposefully made by the financial analysts, since they all operate with a target capital structure. 
At least three of the spreadsheet models estimate firm values that deviate considerably from firm value estimated by a control model with no methodological errors; even though the exact size of the errors cannot be determined. The implications of those errors may be significant. Investors are exposed to poor recommendations and run the risk of carrying out unprofitable transactions. Financial institutions such as investment bankers and stockbrokers are exposed to bad reputation and lawsuits. Accountants must be able to carry out firm valuation for impairment testing purposes. Again, the consequences for accountants may be severe; bad reputation, the risk of litigations etc.

Considering the impact that methodological errors have on firm value estimates it is surprising that this field of study has only received modest attention. It seems illogical to spend considerable resources in collecting and analyzing data and create pro-forma financial statements without ensuring that the output (firm value estimate) is not flawed. The empirical findings of our study suggest that future research in the application and implementation of firm valuation in practice is warranted.

\section{ACKNOWLEDGEMENTS}

We are grateful to Michael Hansen and Peter Lejre who have been helpful in collecting data.

\section{REFERENCES}

1. Copeland, T., T. Koller and J. Murrin. (2000). Valuation-Measuring and managing the value of companies. $3^{\text {rd }}$ edition. New York: Wiley \& Sons.

2. Courteau, L. J. Kao and G. Richardson. (2001). Equity valuation employing the ideal versus ad hoc terminal value expressions. Contemporary Accounting Research, 18: 625-661.

3. Demirakos, D.G., N. Strong and M. Walker. (2003). The valuation methodologies of financial analysts. Working Paper, Manchester School of Accounting and Finance.

4. Francis, J., P. Olsson and D. Oswald. (2000). Comparing the accuracy and explainability of dividend, free cash flow and abnormal earnings equity value estimates. Journal of Accounting Research, 38: 45-70.

5. Levin, J. (1998). On the general equivalence of company valuation models. In Levin, J. Essays in Company Valuation. Stockholm School of Economics, EFI: 235-333.

6. Levin, J. and P. Olsson. (1998). Company valuation with a periodically adjusted cost of capital. In Olsson, P. Studies in Company Valuation. Stockholm School of Economics: EFI: 266-301.

7. Levin, J. and P. Olsson. (2000). Terminal value techniques in equity valuation - implications of the steady state assumption. Working Paper, Stockholm School of Economics.

8. Levin, J. (2000). Why theoretically equivalent models give different results. Working Paper, Stockholm School of Economics.

9. Lundholm, R. and T. O'Keefe. (2001a). Reconciling value estimates from the discounted cash flow model and the residual income model. Contemporary Accounting Research, 18 (Summer): 311-335.

10. Lundholm, R. and T. O'Keefe. (2001b). On comparing residual income and discounted cash flow models of equity valuation: A response to Penman 2001. Contemporary Accounting Research, 18 (Winter): 693696.

11. Modigliani, F. and M. H. Miller. (1958). The cost of capital, corporation finance and the theory of investment. American Economic Review 48: 261-297.

12. Ohlsson, J. A. (1995). Earnings, book values, and dividends in equity valuation, Contemporary Accounting Research 11 (Spring): 661-687.

13. Palepu, K., V. Bernard and P. Healy (1996). Business analysis and Valuation: Using Financial Statements. Cincinatti, Ohio: South-Western College Publishing.

14. Panko, R. R. (2000). Two Corpuses of Spreadsheet Error, Proceedings of the Thirty-Third Hawaii International Conference on System Sciences, Maui, Hawaii

15. Penman, S. (1997). A synthesis of equity valuation techniques and the terminal value calculation for the dividend discount model. Review of Accounting Studies, 2 (4): 303-323.

16. Pratt, S.P, R.F. Reilly and R.P. Schweihs (2000). Valuing a Business: The analysis and appraisal of closely held companies. McGraw-Hill. 
17. Penman, S. and T. Sougiannis. (1998). A comparison of dividend, cash flow and earnings approaches to equity valuation. Contemporary Accounting Research, 15 (3): 343-383.

18. Sweeney, R.J. (2002). Accrual-accounting versus cash flow valuations. Working Paper, Georgetown University

\section{ENDNOTES}

${ }^{1}$ All three papers acknowledge that the models are equivalent in theory.

${ }^{2}$ If the free cash flow to the firm is replaced by the free cash flow to equity, the DCF model measures the market value of equity (as does model 1 and 2).

${ }^{3}$ In the remaining part of this study valuation approaches refers to present value approaches.

${ }^{4}$ As mentioned above, Lundholm and O'Keefe (2001a) define the three categories as inconsistent forecasts errors, incorrect discount errors and missing cash flow errors.

${ }^{5}$ Terminal value $=\frac{F C F}{W A C C-g}$

${ }^{6}$ For example if inventory at the beginning of the period is measured as a percentage of revenue or depreciation is measured as a percentage of fixed assets at the beginning of the period.

7 Terminal value $=\frac{\text { NOPAT }}{\text { WACC }}$

${ }^{8}$ Additional assumptions include that cost of capital must exceed the growth rate and that pro forma financial statements are based on clean surplus (Ohlson 1995). A preliminary examination of the five valuation models applied by our sample firms reveals that our sample firms do not violate these additional assumptions

${ }^{9}$ Due to the transparency of the Danish market, we cannot be more specific without revealing the identity of the financial institutions that participated in the analysis.

${ }^{10}$ Demirakos et al. (2003) also find that the DCF approach is far more popular than the EVA approach. Based on an examination of 105 analysts' reports from international investment banks they find that the RI approach is only applied in two cases. The DCF approach is applied in 38 reports.

${ }^{11}$ In addition financial analysts often check if their firm value estimates seem reasonable by applying multiples (e.g., priceearnings or price-to-book ratios).

${ }_{12}^{12}$ Due to differences in the design of the spreadsheets (valuation models) and type of errors our questions were case specific.

${ }^{13}$ If interest rates are floating book values should mirror market values. If interest rates are fixed book value may be a fair proxy for market value unless interest rates fluctuate considerable.

${ }^{14} \mathrm{FCF}_{\mathrm{T}} \cdot(1+\mathrm{g})$.

$15 \frac{F C F_{T+1}}{W A C C-g}$.

${ }^{16}$ Net Operating Profit Less Adjusted Taxes.

${ }^{17}$ We ensured that the control model was not prone to errors in a number of ways. For example, we valued the fictitious firm with different valuation models (e.g., DCF-model and RI-model) and our estimates turned out to be exactly the same

irregardless of the model employed. We also made all kinds of sensitivity checks and still the models yielded consistently the same value estimates (though different values for each sensitivity check).

${ }^{18}$ However, even this estimate is highly uncertain. For example, we assume that the error only relate to the explicit forecast period and not the terminal period. If the error also relates to the terminal period depends on the value driver setup in the valuation model.

${ }^{19}$ The opposite view may also be the case. That is financial institutions that participate did so because the expected that they had implemented the valuation models correctly. 


\section{NOTES}

